\title{
CLOCK 3111TT Genotype Is Associated with Increased Total Cholesterol and Low-Density Lipoprotein Levels in Menopausal Women with a Body Mass Index of at Least $25 \mathrm{~kg} / \mathrm{m}^{2}$
}

\author{
Natalya Semenova *, Irina Madaeva, Sergey Kolesnikov (D), Lyubov Rychkova, Tatjana Bairova, \\ Marina Darenskaya (D) and Lyubov Kolesnikova
}

Citation: Semenova, N.; Madaeva, I.; Kolesnikov, S.; Rychkova, L.; Bairova, T.; Darenskaya, M.; Kolesnikova, L. CLOCK 3111TT Genotype Is Associated with Increased Total Cholesterol and Low-Density Lipoprotein Levels in Menopausal Women with a Body Mass Index of at Least $25 \mathrm{~kg} / \mathrm{m}^{2}$. Pathophysiology 2021, 28,1-9. https://doi.org/10.3390/ pathophysiology28010001

Received: 16 November 2020 Accepted: 29 December 2020 Published: 30 December 2020

Publisher's Note: MDPI stays neutral with regard to jurisdictional clai$\mathrm{ms}$ in published maps and institutional affiliations.

Copyright: (C) 2020 by the authors. Licensee MDPI, Basel, Switzerland. This article is an open access article distributed under the terms and conditions of the Creative Commons Attribution (CC BY) license (https:// creativecommons.org/licenses/by/ $4.0 /)$.
Scientific Centre for Family Health and Human Reproduction Problems, 664003 Irkutsk, Russia; nightchild@mail.ru (I.M.); sikolesnikov2012@gmail.com (S.K.); rychkova.nc@gmail.com (L.R.); tbairova38@mail.ru (T.B.); marina_darenskaya@inbox.ru (M.D.); kolesnikova20121@mail.ru (L.K.)

* Correspondence: natkor_84@mail.ru; Tel.: +73-952-207-636

Abstract: Lipid profile comparative analysis was performed to reveal the interdependence of lipids with Circadian locomoter output cycles protein kaput (CLOCK) 3111T/C gene polymorphism in menopausal women with/without a body mass index (BMI) of $\geq 25 \mathrm{~kg} / \mathrm{m}^{2}$. Methods: A total of 193 female volunteers aged 45 to 60 years were divided into two groups: Those with BMI $<25 \mathrm{~kg} / \mathrm{m}^{2}$ (control) and those with BMI $\geq 25 \mathrm{~kg} / \mathrm{m}^{2}$. Each group was then divided into two subgroups: Those with the CLOCK TT-genotype and those with the CLOCK TC-, CC-genotypes. Lipid metabolism parameters were determined by the enzymatic method. Single-nucleotide polymorphisms (SNPs) were detected via polymerase chain reaction-restriction fragment length polymorphism technology. Results: There were no differences in CLOCK 3111T/C genotypes or allele frequency between the control and main groups. In addition, there were no differences in lipid profile parameters between women of the control group and different CLOCK 3111T/C genotypes. The total cholesterol $(p=0.041)$ and low-density lipoprotein cholesterol $(p=0.036)$ levels were higher in the subgroup of women with a BMI $\geq 25 \mathrm{~kg} / \mathrm{m}^{2}$ and CLOCK TT-genotype as compared to the subgroup with a BMI $\geq 25 \mathrm{~kg} / \mathrm{m}^{2}$ and minor allele 3111C. Conclusions: SNP 3111T/C of the CLOCK gene is not associated with BMI however, data suggest that the minor allele of the CLOCK 3111T/C gene polymorphism may have a protective role in atherogenic lipid levels in women with a BMI greater than or equal to $25 \mathrm{~kg} / \mathrm{m}^{2}$.

Keywords: CLOCK 3111T/C polymorphism; atherogenic lipids; body mass index

\section{Introduction}

The prevalence of being overweight and obesity is growing steadily in developed and developing countries [1]. It is known that being overweight can contribute to the development of diseases such as diabetes [2], cardiovascular diseases [3], asthma [4], cancer [5], and others. In this context, the task of finding predictors of being overweight does not lose its relevance.

Accumulated to date, some research results indicate that many metabolic and physiological functions are controlled by the circadian system, including one of its genes the Circadian locomoter output cycles protein kaput (CLOCK) gene. Its participation in the regulation of circadian rhythms is noted in the transcription-translation feedback loops and occurs through the dimerization of its protein product with the Brain muscle arnt-like (BMAL1) protein in the cell nucleus [6]. Currently, the single-nucleotide substitution in the $3^{\prime}$-untranslated region (UTR) of the CLOCK gene $(3111 T / C, r s 1801260)$ is the most studied. Associations of this single-nucleotide polymorphism (SNP) were identified not only with the sleep-wake cycle [7-10], but also with body weight [11,12]. Therefore, it has 
been shown that individuals with a $C$-allele have lower body weight [11] and are less likely to be overweight [12]. Some studies have drawn opposite conclusions [13]. In a study examining the effect of diet on the lipid profile in overweight and obese patients, including those with metabolic syndrome and coronary heart disease, there were no differences in lipid profile parameters in groups with different 3111T/C SNPs of their CLOCK gene [14-16]. It should be noted that the researchers did not differentiate their groups by gender, although it has been found that $3111 \mathrm{~T} / \mathrm{C}$ SNP of the CLOCK gene is associated with the risk of overweight/obesity only in women $[17,18]$.

It is known that being overweight and obesity occur in more than $60 \%$ of menopausal women [19]. This is due to involutional hormonal changes, primarily estrogen deficiency $[20,21]$. At the same time, given the above studies, it becomes clear that studies on the SNP 3111T/C of the CLOCK gene and lipid profile association in this population cohort are needed. The results of studies by Galbete $C$ et al. (2012) showed that the minor allele SNP 3111T/C of the CLOCK gene could be associated with decreased overweight/obesity risk in elderly women [17]. A study involving girls showed $C$-allele and an increased body mass index (BMI) association [18]. Data on lipid profile parameters depending on the studied polymorphism genotype were not presented in either study. Given the multidirectional results of these studies, it is necessary to study the possible associations of SNP 3111T/C of the CLOCK gene with the lipid profile separately in each age group. The high prevalence of obesity in menopausal women was the reason for choosing this critical period of life to study the effect of SNP 3111T/C in the CLOCK gene on lipid outcomes. The obtained results can be used to prevent the development of lipid metabolism disorders.

The hypothesis of this study was a possible influence of CLOCK SNP on BMI and the lipid profile in menopause. To confirm this hypothesis, we carried out lipid profile comparative analysis in menopausal women with a BMI $<25 \mathrm{~kg} / \mathrm{m}^{2}$ and those with a BMI $\geq 25 \mathrm{~kg} / \mathrm{m}^{2}$ to reveal its interdependence with genotype regarding $3111 T / C$ SNP of the CLOCK gene.

\section{Materials and Methods}

\subsection{Standard Protocol Approvals, Registrations, and Patient Consent}

The study was carried out in the Federal State Public Scientific Institution "Scientific Centre for Family Health and Human Reproduction Problems" with the informed consent of the participants as provided for by the Ethical norms of the Declaration of Helsinki of the World Medical Association (2013) [22]. The research protocol was approved by the Committee on Biomedical Ethics of this Scientific Centre (protocol no. 8 dated 15 December 2016).

\subsection{Subjects}

This retrospective study involved 193 Caucasian peri- and postmenopausal womenvolunteers aged from 45 to 60 years who were recruited through personal interviews. The research program was conducted and included the following methods: Clinical-anamnestic (medical history, physical examination, and gynecological examination), laboratory (molecular genetic testing and examination of lipid profile parameters), and statistical. Inclusion criteria for the perimenopausal group were as follows: Aged 45-55 years; oligomenorrhea or amenorrhea during the previous 12 months; mismatch of the structure and thickness of the endometrium corresponding to the first and the second phases of the menstrual cycle; and depletion of the follicular reserve of ovaries. Inclusion criteria for the postmenopausal group were as follows: Aged 56-60 years; amenorrhea for $\geq 12$ months; a follicle-stimulating hormone level of $>20 \mathrm{iU} / \mathrm{mL}$, luteinizing hormone/follicle-stimulating hormone index $<1$; thin non-functional endometrium, with endometrial echo thinner than $5 \mathrm{~mm}$; and a lack of follicular reserve of ovaries. The exclusion criteria were as follows: Hormone replacement therapy; the use of lipid-lowering medication; and surgical menopause.

Women were categorized based on the results of clinical-anamnestic examination and according to the World Health Organization BMI ranges [1] as normal weight $\left(18.5-24.9 \mathrm{~kg} / \mathrm{m}^{2}\right)$ (control), overweight $\left(25.0-29.9 \mathrm{~kg} / \mathrm{m}^{2}\right)$, or obese $\left(30.0 \mathrm{~kg} / \mathrm{m}^{2}\right.$ or above). Subjects that 
were overweight and had obesity were merged into the main group (those with BMI of $\geq 25 \mathrm{~kg} / \mathrm{m}^{2}$ ). The basic characteristics of the groups are demonstrated in Table 1 .

Table 1. Profile of women with different body mass index (BMI).

\begin{tabular}{|c|c|c|}
\hline Characteristics & $\mathrm{BMI}<25, n=42$ & $\mathrm{BMI} \geq 25, n=151$ \\
\hline Age, year & $52 \pm 4.74$ & $53 \pm 5.15$ \\
\hline Height, $m$ & $1.62 \pm 0.06$ & $1.61 \pm 0.07$ \\
\hline Weight, kg & $59.9 \pm 6.54$ & $81.1 \pm 13.21$ \\
\hline BMI, $\mathrm{kg} / \mathrm{m}^{2}$ & $23.1 \pm 1.51$ & $31.2 \pm 4.95 *$ \\
\hline Perimenopause, $n(\%)$ & $20(47.62)$ & $61(40.4)$ \\
\hline Postmenopause, $n(\%)$ & $22(52.38)$ & $90(59.6)$ \\
\hline
\end{tabular}

\subsection{Methods and Elaborating on Methods}

\subsubsection{Obesity-Related Parameters}

The anthropometric measurements were performed in the morning, from 8:00 to 9:00 a.m. before blood sampling after an overnight fast beginning at 10:00 p.m. the previous night. Weight was measured to the nearest $0.1 \mathrm{~kg}$ using a balance scale, in light clothing, without shoes. Height was determined using a fixed wall stadiometer to the nearest $0.1 \mathrm{~cm}$. The BMI was calculated as the weight in kilograms divided by the square of the height in meters.

\subsubsection{Collection of Material}

Between 8.00 and 9.00 a.m., after $12 \mathrm{~h}$ of overnight fasting, venous blood was sampled from the cubital vein into two tubes with tripotassium ethylenediaminetetraacetic acid anticoagulant. Whole venous blood from the first tube served as the material for molecular genetic examination. Samples from the second tube were centrifuged for $10 \mathrm{~min}$ at $1.500 \times \mathrm{g}$ at $4{ }^{\circ} \mathrm{C}$ and blood serum was used immediately for total cholesterol (TC), high-density lipoprotein cholesterol (HDL-C), and triacylglycerol (TG) determination.

\subsubsection{Molecular Genetic Examination}

The study participants were genotyped according to the 3111T/C SNP of their CLOCK gene ( $r$ 1801260). Subsequently, genomic DNA was extracted from the blood samples using the "AmpliPrime DNA-Sorb-B" reagent kit ("Nekstbio", Moscow, Russia). The polymorphic marker was determined using polymerase chain reaction-restriction fragment length polymorphism technology on the "DT-Prime" ("DNA-Technology", Moscow, Russia) amplifier using reagent sets for genotyping polymorphic markers ("TestGen", Ulyanovsk, Russia). The 3111T/C SNP of the CLOCK gene was amplified using forward (5'- TCC AGC AGT TTC ATG AGA TGC-3') and reverse (5'-GAG GTC ATT TCA TAG CTG AGC-3') primers. Amplification was carried out under the following conditions: $94^{\circ} \mathrm{C}$ for $4 \mathrm{~min}$, followed by five cycles of $95^{\circ} \mathrm{C}$ for $30 \mathrm{~s}, 58^{\circ} \mathrm{C}$ for $30 \mathrm{~s}$, and $72{ }^{\circ} \mathrm{C}$ for $60 \mathrm{~s}$; thereafter, 30 cycles of $95^{\circ} \mathrm{C}$ for $30 \mathrm{~s}, 55^{\circ} \mathrm{C}$ for $30 \mathrm{~s}$, and $72{ }^{\circ} \mathrm{C}$ for $60 \mathrm{~s}$. The SNP was identified by restriction of the $221 \mathrm{bp}$ PCR-fragment with the restriction enzyme Bsp1286I at $37^{\circ} \mathrm{C}$ for $5 \mathrm{~h}$ and the $\mathrm{C}$-allele was cut by Bsp1286I. The resulting fragments were visualized on a $3 \%$ agarose gel under ultraviolet light after ethidium bromide staining. The electrophoresis results were recorded and documented using the GelDoc computerized gel documentation system.

\subsubsection{Plasma Lipid Determination}

TC, HDL-C, and TG levels were measured photometrically using PLIVA-Lachema kits (Brno, Czech Republic) on a BTS-330 automatic analyzer (Barcelona, Spain). The lowdensity lipoprotein cholesterol (LDL-C) and very-low-density lipoprotein cholesterol (VLDL-C) levels in serum were estimated mathematically using the Friedewald formula [23]. This formula was used because the TG levels were less than $4.5 \mathrm{mmol} / \mathrm{L}$. LDL-C was cal- 
culated as TC-HDL-C-VLDL-C, and VLDL-C was calculated as TG/2.2 because the unit is $\mathrm{mmol} / \mathrm{L}$.

\subsubsection{Statistics}

The obtained data were processed in STATISTICA 10 (Stat-Soft Inc, Tulsa, OK, USA). A power calculation was not performed for this retrospective genotyping analysis. To determine the proximity to the normal law of distribution of quantitative signs, the visualgraphic method and the Kolmogorov-Smirnov test were used. The Fisher test was used to determine the equality of the general variances. Lipid profile parameters were characterized by a non-normal distribution therefore, the assessment of these parameters' differences between the studied groups was carried out by a nonparametric method of statistical analysis using the Mann-Whitney $U$-test. Lipid profile data are presented as median [quartile 1 (Q1); quartile 3 (Q3)]. Data on age, weight, height, and BMI followed a normal distribution and were analyzed using the parametric Student $t$-test. These data are presented as arithmetic mean \pm standard deviation. The distribution of the genotypes of the investigated polymorphism was tested for compliance with the Hardy-Weinberg law. Comparisons of the frequencies of alleles and genotypes within and between the targeted groups were carried out using the Pearson $\chi^{2}$ test with Yates correction for continuity if the value of at least one cell of the conjugation table was less than 5 . The genotypes and the overweight risk association were assessed by determining the odds ratios. Discriminant analysis to select the most informative parameters underlying the division of groups with different genotypes was used. All the differences were considered statistically significant at $p<0.05$.

\section{Results}

A comparative analysis of the distribution of alleles of the CLOCK 3111T/C gene polymorphic marker was conducted for the studied groups of women (Table 2). In both groups, the distribution of the genotypes corresponded to the Hardy-Weinberg distribution law $(p>0.05)$. In both groups, normal weight and overweight women, the 3111T-allele and the TT-genotype were more prevalent. There were no statistically significant differences in the frequency of occurrence of the genotypes and alleles of the studied SNP between the compared groups.

Table 2. The frequencies of the Circadian locomoter output cycles protein kaput (CLOCK) 3111T/C (rs 1801260) gene polymorphism genotypes and alleles in the groups.

\begin{tabular}{|c|c|c|c|c|c|c|c|c|c|}
\hline \multirow{3}{*}{ Group } & \multirow{2}{*}{\multicolumn{3}{|c|}{ Genotypes, $n(\%)$}} & \multirow{2}{*}{\multicolumn{2}{|c|}{ Alleles }} & \multicolumn{4}{|c|}{ Compliance with the Hardy-Weinberg Law } \\
\hline & & & & & & \multicolumn{3}{|c|}{ Expected Genotype Frequency (\%) } & \multirow{2}{*}{$p$-Value } \\
\hline & $3111 T / T$ & $3111 T / C$ & $3111 C / C$ & $3111 T$ & $3111 C$ & $3111 T / T$ & $3111 T / C$ & $3111 C / C$ & \\
\hline $\mathrm{BMI}<25 \mathrm{~kg} / \mathrm{m}^{2}$ & $22(52.4)$ & $16(38.1)$ & $4(9.5)$ & 0.71 & 0.29 & 51.05 & 40.8 & 8.15 & $>0.05$ \\
\hline \multirow{2}{*}{$\mathrm{BMI} \geq 25 \mathrm{~kg} / \mathrm{m}^{2}$} & $76(50.3)$ & $56(37.1)$ & $19(12.6)$ & 0.69 & 0.31 & 47.4 & 42.89 & 9.7 & $>0.05$ \\
\hline & \multicolumn{3}{|c|}{$\chi^{2}=0.294 ; \mathrm{df}=2 ; p=0.864$} & \multicolumn{2}{|c|}{$\chi^{2}=0.202 ; \mathrm{df}=1 ; p=0.654$} & & & & \\
\hline
\end{tabular}

When calculating the odds ratios of the risk of overweight depending on the genotype, no association was found (Table 3).

Table 3. The odds ratios of the risk of being overweight depending on the genotype.

\begin{tabular}{ccc}
\hline Overweight Risk Factor & OR $\mathbf{( 9 5 \% ~ C I )}$ & $p$-Level \\
\hline TT-genotype & $0.92(0.47-1.83)$ & $>0.05$ \\
$T C-$, CC-genotypes & $1.09(0.55-2.15)$ & $>0.05$ \\
\hline
\end{tabular}

The results of the discriminant analysis showed that the most informative lipid profile parameters distinguishing the group with the TT-genotype from the group with the TC-, $C C$ genotypes were TC $(\mathrm{F}=14.71 ; p=0.000)$ and LDL-C $(\mathrm{F}=27.22 ; p=0.000)$. The square of the 
Mahalonobis distance was $1.23(p=0.000)$. Recalculation of the parameters' informativeness as a percentage showed the contribution of TC to be $28.5 \%$ and that of LDL-C to be $44 \%$.

Table 4 summarizes the lipid profile parameters in women with/without a BMI of $\geq 25 \mathrm{~kg} / \mathrm{m}^{2}$ differentiated as carriers of different genotypes of 3111T/C SNP of the CLOCK gene. Given the small number of women carrying the CC-genotype of the CLOCK 3111T/C gene, the carriers of the CC-genotype and TC-genotype were combined into one group as carriers of the minor 3111C-allele. There were no statistically significant differences in the lipid profile parameter levels in the group with normal-weight carriers of different SNP genotypes (the TT-genotype and the TC-, CC-genotypes). When comparing the given women with a BMI $\geq 25 \mathrm{~kg} / \mathrm{m}^{2}$, significantly higher TC and LDL-C levels were detected in the carriers of the TT-genotype as compared to the carriers of the minor 3111C-allele $(p<0.05)$. A comparative analysis of the lipid profile between groups with a normal weight and were overweight showed higher levels of TC, TG, and LDL-C and lower HDL-C levels in women with a BMI $\geq 25 \mathrm{~kg} / \mathrm{m}^{2}$ who are carriers of the TT-genotype, as compared to the group with normal weight and the TT-genotype $(p<0.05)$. The carriers of the minor allele with a BMI $\geq 25 \mathrm{~kg} / \mathrm{m}^{2}$ had higher TC, TG, and LDL-C levels as compared to the group with normal weight and the 3111C-allele $(p<0.05)$.

Table 4. BMI and lipid profile parameters in women who are carriers of different CLOCK 3111T/C gene polymorphisms (rs 1801260).

\begin{tabular}{|c|c|c|c|c|c|}
\hline \multirow{2}{*}{ Parameters } & \multicolumn{2}{|c|}{$\mathrm{BMI}<25 \mathrm{~kg} / \mathrm{m}^{2}$} & \multicolumn{2}{|c|}{$\mathrm{BMI} \geq 25 \mathrm{~kg} / \mathrm{m}^{2}$} & \multirow{2}{*}{$p$-Value } \\
\hline & $3111 T / T$ & $3111 T / C+3111 C / C$ & $3111 T / T$ & $3111 T / C+3111 C / C$ & \\
\hline & $n=22$ & $n=20$ & $n=76$ & $n=75$ & \\
\hline $\mathrm{BMI}\left(\mathrm{kg} / \mathrm{m}^{2}\right)$ & $23.2 \pm 1.66$ & $23 \pm 1.35$ & $31.1 \pm 4.46$ & $31.2 \pm 5.44$ & $\begin{array}{l}p^{a, c}=0.009 \\
p^{b, d}=0.001 \\
p^{a, c}=0.013\end{array}$ \\
\hline $\mathrm{TC},(\mathrm{mmol} / \mathrm{L})$ & $4.25[3.70-5.37]$ & 4.39 [3.99-4.53] & $5.29[4.72-6.02]$ & 5.18 [4.09-5.91] & $\begin{array}{l}p^{c, d}=0.029 \\
p^{b, d}=0.033\end{array}$ \\
\hline $\mathrm{TG},(\mathrm{mmol} / \mathrm{L})$ & 0.67 [0.54-0.99] & 0.94 [0.77-1.12] & 0.98 [0.74-1.23] & 1.01 [0.68-1.39] & $\begin{array}{l}p^{a, c}=0.010 \\
p^{b, d}=0.025\end{array}$ \\
\hline HDL-C, (mmol/L) & 1.34 [1.23-1.58] & 1.19 [1.05-1.36] & 1.15 [0.92-1.34] & 1.24 [1.02-1.40] & $\begin{array}{l}p^{a, c}=0.018 \\
p^{a, c}=0.003\end{array}$ \\
\hline LDL-C, $(\mathrm{mmol} / \mathrm{L})$ & $2.60[2.14-3.27]$ & 2.69 [2.33-2.92] & 3.87 [3.10-4.29] & $3.51[2.43-4.06]$ & $\begin{array}{l}p^{c, d}=0.012 \\
p^{b, d}=0.007\end{array}$ \\
\hline VLDL-C, (mmol/L) & $0.30[0.24-0.45]$ & $0.43[0.35-0.58]$ & 0.45 [0.34-0.56] & $0.46[0.31-0.64]$ & NS \\
\hline
\end{tabular}

NS-not statistically significant, $p>0.05$. Groups: $a-3111 T / T$, BMI $<25 \mathrm{~kg} / \mathrm{m}^{2} ; b-3111 T / C+3111 \mathrm{C} / \mathrm{C}, \mathrm{BMI}<25 \mathrm{~kg} / \mathrm{m}^{2} ; c-3111 T / T$, $\mathrm{BMI} \geq 25 \mathrm{~kg} / \mathrm{m}^{2} ; d-3111 \mathrm{~T} / \mathrm{C}+3111 \mathrm{C} / \mathrm{C}, \mathrm{BMI} \geq 25 \mathrm{~kg} / \mathrm{m}^{2}$. TC-total cholesterol; HDL-C-high-density lipoprotein cholesterol; TGtriacylglycerol; LDL-C-low-density lipoprotein cholesterol; VLDL-C-very-low-density lipoprotein cholesterol.

\section{Discussion}

It is currently supposed that being overweight may be associated with $3111 T / C$ SNP of the CLOCK gene, but the results of studies on the matter are ambiguous [11-18]. Here, we found no differences in the prevalence of genotypes and alleles of 3111T/C SNP of the CLOCK gene in women that had a normal weight or were overweight. Our data are consistent with the results of a study involving elder women [17]. In addition, similar data were obtained for a sample including both women and men of reproductive age however, the authors then compared groups with a BMI of $\geq 40 \mathrm{~kg} / \mathrm{m}^{2}$ and BMI of $<40 \mathrm{~kg} / \mathrm{m}^{2}$ and found an association of the minor allele with class III obesity [13]. Using these results, we conducted a similar analysis and did not find differences in BMI between groups of different genotypes with being overweight. In addition, among the participants in our study with the CC-genotype, there were no women with a BMI of $>40 \mathrm{~kg} / \mathrm{m}^{2}$. A calculation of the odds ratios of overweight realization in groups with the TT-genotype and TC-, CC-genotypes also showed no association of genotypes with being overweight. Based on our results, it can be assumed that the SNP 3111T/C of the CLOCK gene is not associated with being overweight in menopausal women. 
Using multivariate discriminant analysis, we tried to determine the most informative lipid parameters according to which groups with different genotypes differ, but without dividing by BMI. It turned out that the greatest contribution to the difference between the groups was made by LDL-C and TC. To understand whether BMI affects lipid outcomes across genotypes, we analyzed groups with a normal BMI and those who were overweight. The results obtained indicate increased LDL-C and TC levels in women with the TTgenotype in the overweight group. Our results are, to some extent, consistent with the results of a study by Tsuzaki K. et al. (2010), who showed that in TT-homozygotes, the area of sdLDL-C was greater compared with that in carriers of the $C$-allele. Their group was not divided according to gender or age, including participants aged 24 to 88 [24]. In turn, the results of some studies on a potential association of SNP 3111T/C of the CLOCK gene and obesity showed that gender and age are important factors influencing the outcome. In a recent study involving schoolchildren, an association of the minor allele with being overweight was found only in girls [18]. Opposite results, which are consistent with our data, were obtained with elder women [17]. A possible reason for these differences may be different sex hormone levels.

Many studies have shown a regulatory role for estradiol in lipid metabolism and food intake [25,26]. The results of a recent experimental study showed that the estradiol synthesis in granulosa cells is regulated by melatonin. At the same time, it was shown that low melatonin concentrations have an effect on 89 differentially expressed genes associated with steroid hormone synthesis, cell proliferation and cell cycle regulation, positive regulation of the nitrogen compound metabolic process, oxidoreductase activity, and anti-apoptosis regulation [27].

We currently know about age-related decreases in melatonin concentration, indicating a decrease in the melatonin-forming function of the pineal gland, which is a consequence of functional changes in the pineal gland and in other links of the circadian system of the body during physiological aging [28]. It has been shown that melatonin rhythms in menopausal Caucasian women are associated with 3111T/C SNP of the CLOCK gene. A shift of the melatonin peak to the early morning hours was recorded in carriers with the major allele [10], which is considered a possible cause of the development of oxidative stress in these women [29]. In turn, oxidative stress leads to epigenetic changes that involve chromatin remodeling via alterations in transcriptional regulators with a modification of histones leading to metabolic disorders with neurodegeneration [30].

One of the genes associated with the circadian clock is SIRT 1. It is possible that SIRT 1 defects lead to suprachiasmatic nucleus in the hypothalamus, defects that are related to peripheral circadian clock dyssynchrony and changes in melatonin levels [31]. It has also been shown that SIRT 1 regulates food intake and body weight [32]. The results of an experiment on mice aiming to study the effect of melatonin on the lipid profile and the development of obesity demonstrated that melatonin supplementation attenuated serum TG, TC, and LDL-C levels and prevented body mass gain through a decreased lipogenesis rate and increased lipolytic capacity in white adipocytes, with a concomitant increment in oxygen consumption and PGC1A and PRDM16 expression [33]. Taking these results into account, we suggest that the TC and LDL-C level increases in overweight women with $3111 T / C$ SNP of the CLOCK gene major allele in our study may be associated with melatonin secretion changes.

The results of a recent study on the functional role of $3111 \mathrm{~T} / \mathrm{C}$ polymorphism of the CLOCK gene showed that the $C$-allele, as compared to the $T$-allele, leads to higher CLOCK mRNA levels and a high expression of PER2-a CLOCK transcriptional target-thereby changing the other clock molecules' network and circadian rhythmicity. It is assumed that these changes may be due to different mechanisms, including the binding sites of miRNA-182 in the $3^{\prime}$-UTR of the CLOCK gene [34].

Among the studies on this topic, we found a series of investigations indicating lower adiponectin and high ghrelin levels in overweight and obese people with 3111T/C SNP of the CLOCK gene's minor allele $[35,36]$. It is known that adiponectin has an anti-atherogenic 
effect [37] and ghrelin is an important factor linking the central nervous system with peripheral tissues that regulate lipid metabolism [38].

\section{Conclusions}

In conclusion, the present results showed that menopausal women with a BMI $\geq 25 \mathrm{~kg} / \mathrm{m}^{2}$ and the TT-genotype had higher TC and LDL-C levels when compared to carriers of the minor allele, which may play a protective role in the atherogenic lipid levels in these women. There are some limitations to our study. First of all, the number of women in the groups was limited. Studies with larger cohorts may find lipid profile changes in menopausal women with the homozygous CC-genotype. Secondly, our study included only menopausal women. Similar studies with women of reproductive age may reveal the influence of age on an association of 3111T/C SNP of the CLOCK gene and lipid metabolism. Thirdly, the study did not include estrogen data. Determination of female sex hormones may demonstrate an association of the SNP and estrogens. In addition, the contribution of other components of the circadian oscillator to genetic susceptibility to overweight should be investigated.

Author Contributions: Conceptualization, N.S. and L.K.; methodology, I.M. and N.S.; validation, S.K.; formal analysis, N.S. and M.D.; investigation, N.S. and I.M.; resources, L.R. and T.B.; writingoriginal draft preparation, N.S.; writing - review and editing, I.M., S.K. and L.K.; project administration, N.S., I.M. and L.K.; funding acquisition, L.R. All authors have read and agreed to the published version of the manuscript.

Funding: This research received no external funding.

Institutional Review Board Statement: The study was conducted according to the guidelines of the Declaration of Helsinki, and approved by the Committee on Biomedical Ethics of Scientific Centre for Family Health and Human Reproduction Problems (protocol no. 8 dated 15 December 2016).

Informed Consent Statement: Informed consent was obtained from all subjects involved in the study. Data Availability Statement: Restrictions apply to the availability of these data.

Acknowledgments: This work was performed with the use of equipment from the Collective research center "Center for the development of progressive personalized technologies for health" SC FHHRP, Irkutsk.

Conflicts of Interest: The authors declare no conflict of interest.

\section{References}

1. World Health Organization. Obesity and Overweight; World Health Organization: Geneva, Switzerland, 2017.

2. Polsky, S.; Ellis, S.L. Obesity, insulin resistance, and type 1 diabetes mellitus. Curr. Opin. Endocrinol. Diabetes Obes. 2015, 22, 277-282. [CrossRef] [PubMed]

3. Seravalle, G.; Grassi, G. Obesity and hypertension. Pharmacol. Res. 2017, 122, 1-7. [CrossRef] [PubMed]

4. Peters, U.; Dixon, A.E.; Forno, E. Obesity and asthma. J. Allergy Clin. Immunol. 2018, 141, 1169-1179. [CrossRef] [PubMed]

5. Katz, A. CE: Obesity-related cancer in women: A clinical review. Am. J. Nurs. 2019, 119, 34-40. [CrossRef] [PubMed]

6. Takahashi, J.S. Molecular Architecture of the Circadian Clock in Mammals. In A Time for Metabolism and Hormones; Springer: Cham, Switzerland, 2016; pp. 13-24.

7. Benedetti, F.; Dallaspezia, S.; Fulgosi, M.C. Actimetric evidence that Clock 3111T/C SNP influence sleep and activity patterns in patients affected by bipolar depression. Am. J. Med. Genet. B Neuropsychiatr. Genet. 2007, 144B, 631-635. [CrossRef]

8. Antypa, N.; Mandelli, L.; Nearchou, F.A.; Vaiopoulos, C.; Stefanis, C.N.; Serretti, A.; Stefanis, N.C. The 3111T/C polymorphism interacts with stressful life events to influence patterns of sleep in females. Chronobiol. Int. 2012, 29, 891-897. [CrossRef]

9. Ziv-Gal, A.; Flaws, J.A.; Mahoney, M.M.; Miller, S.R.; Zacur, H.A.; Gallicchio, L. Genetic polymorphisms in the aryl hydrocarbon receptor-signaling pathway and sleep disturbances in middle-aged women. Sleep Med. 2013, 14, 883-887. [CrossRef]

10. Semenova, N.V.; Madaeva, I.M.; Bairova, T.A.; Zhambalova, R.M.; Sholokhov, L.F.; Kolesnikova, L.I. Association of the melatonin circadian rhythms with clock 3111T/C gene polymorphism in Caucasian and Asian menopausal women with insomnia. Chronobiol. Int. 2018, 35, 1066-1076. [CrossRef]

11. Tortorella, A.; Monteleone, P.; Martiadis, V.; Perris, F.; Maj, M. The 3111T/C polymorphism of the CLOCK gene confers a predisposition to a lifetime lower body weight in patients with anorexia nervosa and bulimia nervosa: A preliminary study. Am. J. Med. Genet. B Neuropsychiatr. Genet. 2007, 144B, 992-995. [CrossRef] 
12. Pagliai, G.; Sofi, F.; Dinu, M.; Sticchi, E.; Vannetti, F.; Lova, R.M.; Ordovàs, J.M.; Gori, A.M.; Marcucci, R.; Giusti, B.; et al. CLOCK gene polymorphisms and quality of aging in a cohort of nonagenarians-The MUGELLO Study. Sci. Rep. 2019, 9, 1472. [CrossRef]

13. Monteleone, P.; Tortorella, A.; Docimo, L.; Maldonato, M.N.; Canestrelli, B.; De Luca, L.; Maj, M. Investigation of 3111T/C polymorphism of the CLOCK gene in obese individuals with or without binge eating disorder: Association with higher body mass index. Neurosci. Lett. 2008, 11, 30-33. [CrossRef]

14. Garcia-Rios, A.; Gomez-Delgado, F.G.; Garaulet, M.; Alcala-Diaz, J.F.; Delgado-Lista, F.J.; Marin, C.; Rangel-Zuñiga, O.A.; Rodriguez-Cantalejo, F.; Gomez-Luna, P.; Ordovas, J.M.; et al. Beneficial effect of CLOCK gene polymorphism rs1801260 in combination with low-fat diet on insulin metabolism in the patients with metabolic syndrome. Chronobiol. Int. 2014, 31, 401-408. [CrossRef] [PubMed]

15. Gomez-Delgado, F.; Garcia-Rios, A.; Alcala-Diaz, J.F.; Rangel Zuñiga, O.; Delgado-Lista, J.; Yubero-Serrano, E.M.; Lopez-Moreno, J.; Tinahones, F.J.; Ordovas, J.M.; Garaulet, M.; et al. Chronic consumption of a low-fat diet improves cardiometabolic risk factors according to the CLOCK gene in patients with coronary heart disease. Mol. Nutr. Food Res. 2015, 59, 2556-2564. [CrossRef] [PubMed]

16. Loria-Kohen, V.; Espinosa-Salinas, I.; Marcos-Pasero, H.; Lourenço-Nogueira, T.; Herranz, J.; Molina, S.; Reglero, G.; De Molina, A.R. Polymorphism in the CLOCK gene may influence the effect of fat intake reduction on weight loss. Nutrition 2016, 32, 453-460. [CrossRef] [PubMed]

17. Galbete, C.; Contreras, R.; Martínez, J.A.; Martínez-González, M.A.; Guillén-Grima, F.; Marti, A. Physical Activity and Sex Modulate Obesity Risk Linked to 3111T/C Gene Variant of the CLOCK Gene in an Elderly Population: The SUN Project. Chronobiol. Int. 2012, 29, 1397-1404. [CrossRef]

18. Meng, Y.; Lohse, B.; Cunningham-Sabo, L. Sex modifies the association between the CLOCK variant rs 1801260 and BMI in school-age children. PLoS ONE 2020, 15, e0236991. [CrossRef]

19. Gonçalves, J.T.; Silveira, M.F.; Campos, M.C.; Costa, L.H. Overweight and obesity and factors associated with menopause. Cien Saude Colet. 2016, 21, 1145-1156. [CrossRef]

20. Lumsden, M.A.; Sassarini, J. The evolution of the human menopause. Climacteric 2019, 22, 111-116. [CrossRef]

21. Lizcano, F.; Guzmán, G. Estrogen Deficiency and the Origin of Obesity during Menopause. Biomed. Res. Int. 2014, $2014,757461$. [CrossRef]

22. World Medical Association (WMA). World Medical Association Declaration of Helsinki: Ethical Principles for Medical Research Involving Human Subjects. JAMA 2013, 310, 2191-2194. [CrossRef]

23. Friedewald, W.T.; Levy, R.I.; Fredrickson, D.S. Estimation of the Concentration of Low-Density Lipoprotein Cholesterol in Plasma, Without Use of the Preparative Ultracentrifuge. Clin. Chem. 1972, 18, 499-502. [CrossRef] [PubMed]

24. Tsuzaki, K.; Kotani, K.; Sano, Y.; Fujiwara, S.; Takahashi, K.; Sakane, N. The association of the Clock 3111 T/C SNP with lipids and lipoproteins including small dense low-density lipoprotein: Results from the Mima study. BMC Med. Genet. 2010, 11, 150. [CrossRef] [PubMed]

25. Palmisano, B.T.; Zhu, L.; Stafford, J.M. Estrogens in the regulation of liver lipid metabolism. Adv. Exp. Med. Biol. 2017, 1043, 227-256. [CrossRef] [PubMed]

26. Tian, L.; Shao, W.; Ip, W.; Song, Z.; Badakhshi, Y.; Jin, T. The developmental Wnt signaling pathway effector $\beta$-catenin/TCF mediates hepatic functions of the sex hormone estradiol in regulating lipid metabolism. PLoS Biol. 2019, 17, e3000444. [CrossRef]

27. Liu, Y.; Yang, Y.; Li, W.; Ao, H.; Zhang, Y.; Zhou, R.; Li, K. Effects of melatonin on the synthesis of estradiol and gene expression in pig granulosa cells. J. Pineal. Res. 2019, 66, e12546. [CrossRef]

28. Tan, D.X.; Xu, B.; Zhou, X.; Reiter, R.J. Pineal calcification, melatonin production, aging, associated health consequences and rejuvenation of the pineal gland. Molecules 2018, 23, 301. [CrossRef]

29. Semenova, N.; Madaeva, I.; Bairova, T.; Kolesnikov, S.; Kolesnikova, L. Lipid peroxidation depends on the clock 3111T/C gene polymorphism in menopausal women with insomnia. Chronobiol. Int. 2019, 36, 1399-1408. [CrossRef]

30. Martins, I.J. Increased risk for obesity and diabetes with neurodegeneration in developing countries. J. Mol. Genet. Med. 2013, S1, 001. [CrossRef]

31. Martins, I.J. Single gene inactivation with implications to diabetes and multiple organ dysfunction syndrome. J. Clin. Epigenet. 2017, 3, 24. [CrossRef]

32. Nguyen, L.T.; Chen, H.; Zaky, A.; Pollock, C.; Saad, S. SIRT1 overexpression attenuates offspring metabolic and liver disorders as a result of maternal high-fat feeding. J. Physiol. 2019, 597, 467-480. [CrossRef]

33. De Farias, T.D.S.M.; Cruz, M.M.; De Sa, R.C.D.C.; Severi, I.; Perugini, J.; Senzacqua, M.; Cerutti, S.M.; Giordano, A.; Cinti, S.; Alonso-Vale, M.I.C. Melatonin supplementation decreases hypertrophic obesity and inflammation induced by high-fat diet in mice. Front. Endocrinol. 2019, 10, 750. [CrossRef] [PubMed]

34. Ozburn, A.R.; Purohit, K.; Parekh, P.K.; Kaplan, G.N.; Falcon, E.; Mukherjee, S.; Cates, H.M.; McClung, C.A. Functional implications of the CLOCK 3111T/C single-nucleotide polymorphism. Front. Psychiatry 2016, 7, 67. [CrossRef] [PubMed]

35. Garaulet, M.; Lee, Y.C.; Shen, J.; Parnell, L.D.; Arnett, D.K.; Tsai, M.Y.; Lai, C.-Q.; Ordovas, J.M. Genetic variants in human CLOCK associate with total energy intake and cytokine sleep factors in overweight subjects (GOLDN population). Eur. J. Hum. Genet. 2010, 18, 364-369. [CrossRef] [PubMed] 
36. Garaulet, M.; Tardido, A.E.; Lee, Y.C.; Smith, C.E.; Parnell, L.D.; Ordovás, J.M. SIRT1 and CLOCK 3111T> C combined genotype is associated with evening preference and weight loss resistance in a behavioral therapy treatment for obesity. Int. J. Obes. 2012, 36, 1436-1441. [CrossRef]

37. Yanai, H.; Yoshida, H. Beneficial effects of adiponectin on glucose and lipid metabolism and atherosclerotic progression: Mechanisms and perspectives. Int. J. Mol. Sci. 2019, 20, 1190. [CrossRef]

38. Lv, Y.; Liang, T.; Wang, G.; Li, Z. Ghrelin, a gastrointestinal hormone, regulates energy balance and lipid metabolism. Biosci. Rep. 2018, 38. [CrossRef] 